\title{
Using HCAHPS data to model correlates of medication understanding at hospital discharge
}

\author{
Rebecca J Bartlett Ellis' \\ Karen L Werskey ${ }^{2}$ \\ Rachel M Stangland ${ }^{2}$ \\ Susan Ofner ${ }^{1,3}$ \\ Giorgos Bakoyannis ${ }^{1,3}$ \\ 'Indiana University School of \\ Nursing, Indianapolis, IN, ${ }^{2}$ Schneck \\ Medical Center, Seymour, IN, \\ ${ }^{3}$ Department of Biostatistics, School \\ of Medicine' Indiana University, \\ Indianapolis, IN, USA
}

Correspondence: Rebecca J Bartlett Ellis Science of Nursing Care Department, Indiana University School of Nursing, 600 Barnhill Drive, E423, Indianapolis, IN 46202, USA

Tel +I 3172740047

Fax $+|317278202|$

Email rjbartle@iu.edu
This article was published in the following Dove Press journal:

Nursing: Research and Reviews

3 February 2017

Number of times this article has been viewed

Background: Hospitals are challenged to improve hospital transitions to home and are held accountable through public reporting.

Design: This cross-sectional study used patients' self-reported experience data from the publicly reported Hospital Consumer Assessment of Healthcare Providers and Systems (HCAHPS) survey to describe correlates of medication understanding at hospital discharge, using data collected from adult patients discharged from one Midwestern community hospital ( $\mathrm{N}=154)$.

Results: The final logistic regression model included four correlates of medication understanding: 1) nurse always communicates well, 2) physician always communicates well, 3) new prescriptions during hospital stay, and 4) very good or better mental health, and these classified $72.6 \%$ of the cases. Significant correlates of the patient strongly agreeing that they understood discharge medications were the "nurse always communicates well" (odds ratio $=3.10,95 \%$ confidence interval: $1.25,7.66$ ) and "very good or better self-perceived mental health" (odds ratio $=2.17,95 \%$ confidence interval: $1.02,4.64$ ).

Conclusion: HCAHPS data can be used to model correlates of medication understanding, which are then useful for evaluating intervention effects following quality improvement.

Keywords: medication, nurse communication, provider communication, hospital quality, nurse, nursing, physician, patient experience, patient satisfaction

\section{Introduction}

Safe transfer of medication responsibility from hospitals to patients as they transition to home requires patients to understand each of their medications at discharge. Medication-related errors and discrepancies may occur in as many as 8 out of 10 people discharged from the hospital. ${ }^{1}$ In the United States, it is estimated that medicationrelated errors injure approximately 1.3 million people annually. ${ }^{2}$ Patients are at particular risk following discharge because medication regimen changes often occur during hospitalization, including discontinuation of medications, dosing adjustments, and the addition of new medications. ${ }^{3,4}$ To promote safe medication management following hospital discharge, it is imperative that patients receive high-quality care and that their experiences while in the hospital prepare them for understanding their medications at discharge. Patient-reported perceptions of these experiences and satisfaction with care are direct reflections of hospital quality. ${ }^{5}$

Patients' understanding of each of their medications at discharge can be influenced by a number of provider and patient factors. Recent research has demonstrated a relationship between patients' perceptions of provider communication and perceptions of medication explanations for newly prescribed medications during the hospital stay. ${ }^{6}$ 
This is consistent with evidence from a recent systematic review that suggests that health care provider communication is the most common predictor of patient satisfaction, whereas patient-centered characteristics may vary and should be considered as potential determinants in evaluation of patient satisfaction. ${ }^{7}$ In particular, this review found that interpersonal care and affective behaviors such as respect and courtesy in interactions with nurses and physicians had effects on patients' satisfaction with their care. However, there was inconsistent evidence about the relationships between patients' demographic and psychological characteristics and their overall satisfaction. These inconsistent findings may have resulted from inclusion of studies that used a variety of measures of satisfaction and patient experience. Use of standardized measures may help overcome some of these limitations and be useful to understand provider and patient characteristics associated with patients' perceived understanding of their medications at discharge.

The Hospital Consumer Assessment of Healthcare Providers and Systems (HCAHPS) survey is a standardized national survey of patients' perspectives of and experience with their hospital care and is used across the United States as a measure of patients' hospital experiences. Descriptive summaries from HCAHPS data are publicly reported by the Centers for Medicare and Medicaid Services, which increases transparency and accountability and encourages hospitals to improve the quality of care delivery, based on user evaluation of the care delivery experience. ${ }^{8,9}$ The survey permits health service users to provide feedback on the quality of care received in the hospital, and public reporting allows consumers to make meaningful comparisons in selecting care delivery. ${ }^{9}$ Further, these data are used to financially incentivize hospitals to improve care quality and are tied to reimbursement. Because it is important for patients to understand their medications at discharge, the HCAHPS survey has a publicly reported measure of patients' perceptions of how well they understand the purpose of their medications at the time of hospital discharge. As hospitals are faced with the challenge of improving the quality of care delivery and held accountable to improve their HCAHPS scores, it is critical to effectively understand the variables associated with patients' medication understanding at hospital discharge from the patients' perspectives. Because the HCAHPS are standardized, we can address previous limitations in survey instruments and diversity in ways of measuring patient experience and satisfaction in evaluating associations among variables and medication understanding at hospital discharge. Using HCAHPS data to identify correlates of patients' perceptions of understanding of medications at discharge can be useful to design interventions and improve outcomes, targeting important variables.

The purpose of this study was to use HCAHPS survey data to examine relationships among patient-reported perceptions of health care provider communication, whether new medications were prescribed during hospitalization or not, and patients' understanding of the purpose of their medications at hospital discharge. We further examined relationships between demographic variables, patient-reported overall health and emotional health status with new medications, and the communication variables on understanding of medications at discharge, given inconsistencies in the literature that suggest patient characteristics may be associated with patient's experience and satisfaction. We hypothesized that patients who perceived nurse communication and physician communication more positively also would report greater understanding of their medications at discharge. We hypothesized that having new medications prescribed during the hospital stay would moderate the relationship between nurse/physician communication and patients' understanding of their medications at discharge.

\section{Methods Design and sample}

This cross-sectional study used existing survey data collected using HCAHPS survey. Data were collected from adult patients (age 18 years or older) who were discharged from one community hospital in a Midwestern city between October 2014 and April 2015. Publicly reported HCAHPS data for this facility during 2015 indicate a survey response rate of $27 \%$. Participants were required to have had at least one overnight stay in the hospital. Maternity data were excluded. This study was reviewed and approved as an exempt study by Schneck Medical Center's designated Institutional Review Board. Written informed consent was deemed not required by Schneck Medical Center's designated Institutional Review Board because the study used only retrospective, de-identified patient data.

\section{Survey instrument}

The HCAHPS survey is currently a 32-item standardized survey administered to patients discharged from all Medicare-participating hospitals in the United States. ${ }^{10,11}$ A survey vendor is used to send surveys to all patients discharged from the hospital, following a standard protocol for quality assurance and sampling adequacy. ${ }^{10,11}$ Detailed information about the HCAHPS survey is published online at http://www. hcahpsonline.org. For this analysis, we selected items from this survey to include items about nurse communication, 
physician communication, new medications and discharge understanding of medications, and mental health and overall health along with demographic items.

\section{Nurse communication}

Three items on the HCAHPS survey were used to construct the nurse communication variable. ${ }^{12}$ These items included patients' perceptions of how often nurses 1) treated the patient with courtesy and respect, 2) carefully listened to the patient, and 3) explained things in an understandable way. Each was evaluated on a 4-point Likert-type scale with response options of always, usually, sometimes, and never. The nurse communication questions were used to create an indicator that all three questions were answered as always. The percentages of "top-box" responses, which are those that are rated with an "always" response, are publicly reported. Therefore, for this analysis, we dichotomized responses as either " "yes' nurses always communicated well" or " "no" nurses did not always communicate well."

\section{Physician communication}

Likewise, physician communication represented how often physicians 1) treated the patient with courtesy and respect, 2) carefully listened to the patient, and 3) explained things in an understandable way. For analysis purposes, the physician communication variable was coded similarly to the nurse communication variable.

\section{New medications}

One question on the HCAHPS survey asked discharged patients if they were prescribed a new medication during their hospital stay. ${ }^{10}$

\section{Discharge understanding of medications}

Understanding of medications at discharge was assessed with one question on the HCAHPS survey. This question asked patients if they "clearly understood the purpose of taking each medication at the time of discharge." The question used a Likert scale with response options of strongly agree, agree, disagree, and strongly disagree, where higher scores represented better understanding of the purpose of taking each medication at discharge. Patients also indicated that they were not given medications at discharge..$^{13,14}$

\section{Mental health and overall health}

To measure perceived mental health, one question asked patients to rate their mental or emotional health. Similarly, one question asked patients to rate their overall health. Both questions used a 5-point Likert response scale with responses of excellent, very good, good, fair, and poor. ${ }^{10}$

\section{Demographic variables}

Demographic variables abstracted from the HCAHPS survey included age, gender, race, and education.

\section{Data analysis}

The analysis was performed using SAS/STAT ${ }^{\circledR}$ software, Version 9.4 (SAS Campus Drive, Cary, NC, USA) of the SAS System for Windows. Descriptive statistics appropriate for the measurement level (eg, frequencies and percentages for nominal/ordinal; mean and standard deviation for quantitative variables) were used. Patient characteristics, new medication, nurse communication, and physician communication were summarized by the binary outcome and tested using Fisher's exact test or $\chi^{2}$ test for categorical variables or a one-way analysis of variance (ANOVA) for continuous variables. The binary outcome, understanding of discharge medications, was modeled by a logistic regression model with indicators for 1) the nurse always communicates well, 2) the physician always communicates well, 3) new medication tested and 4) the interaction of new medication with nurse and physician communication, tested in separate models. We then built a main effects model, which included new medication, each of the communication variables, regardless of their level of significance, and used backward variable selection for those variables with bivariate tests with a $p$-value of 0.3 or smaller and staying criteria of 0.05 for all other demographic variables. The inclusion of interactions between the communication variables (nurse communication and physician communication) with new medication and with mental health was tested after the selection of the main effects with the backward selection algorithm by a likelihood ratio test. The model classification rate was estimated by means of the C-statistic. Effect size was estimated by Nagelkerke's adjusted coefficient of determination.

\section{Results}

Data from 154 patients were available for analysis. Of those, 104 patients strongly agreed and 50 patients did not strongly agree that they understood each medication at discharge. Summary statistics are reported in Table 1 . This was a predominately white, non-Hispanic sample, which is characteristic of the region. The average age across all patients of 66.0 (SD 14.6) represented a sample of older adults. New 
Table I Patient characteristics

\begin{tabular}{|c|c|c|c|c|}
\hline Variable & Overall & $\begin{array}{l}\text { Strongly } \\
\text { agree }\end{array}$ & $\begin{array}{l}\text { Not } \\
\text { strongly } \\
\text { agree }\end{array}$ & $p$-Value \\
\hline Age & & & & 0.3245 \\
\hline $\mathrm{N}$ & 154 & 104 & 50 & \\
\hline Mean \pm SD & $66.0 \pm 14.6$ & $65.2 \pm 15.0$ & $67.7 \pm 13.6$ & \\
\hline Median & 69.0 & 68.0 & 69.5 & \\
\hline$(\min , \max )$ & $(21.0,95.0)$ & $(21.0,93.0)$ & $(37.0,95.0)$ & \\
\hline Gender & & & & 0.7493 \\
\hline Male & $68(44.2)$ & $45(43.3)$ & $23(46.0)$ & \\
\hline Female & $86(55.8)$ & $59(56.7)$ & $27(54.0)$ & \\
\hline Race & & & & 0.7189 \\
\hline Not Caucasian & $9(5.8)$ & $7(6.7)$ & $2(4.0)$ & \\
\hline Caucasian & 145 (94.2) & $97(93.3)$ & $48(96.0)$ & \\
\hline \multicolumn{5}{|l|}{ Hispanic } \\
\hline Puerto Rican & $\mathrm{I}(0.8)$ & $\mathrm{I}(\mathrm{I} .2)$ & $0(0.0)$ & \\
\hline Education & & & & 0.0773 \\
\hline$\leq 8$ th grade & $5(3.4)$ & I (I.0) & $4(8.5)$ & \\
\hline Some high & $14(9.7)$ & $7(7.1)$ & $7(14.9)$ & \\
\hline school & & & & \\
\hline High school grad & $79(54.5)$ & $59(60.2)$ & $20(42.6)$ & \\
\hline Some college & $37(25.5)$ & $24(24.5)$ & $13(27.7)$ & \\
\hline 4-year college grad & $5(3.4)$ & $3(3.1)$ & $2(4.3)$ & \\
\hline $4+$ years college & $5(3.4)$ & $4(4.1)$ & $\mathrm{I}(2 . \mathrm{I})$ & \\
\hline Missing & 9 & 6 & 3 & \\
\hline Education as & & & & 0.7717 \\
\hline \multicolumn{5}{|l|}{ dichotomous } \\
\hline $\begin{array}{l}\text { High school or } \\
\text { less }\end{array}$ & $98(67.6)$ & $67(68.4)$ & $31(66.0)$ & \\
\hline Some college & $47(32.4)$ & $31(31.6)$ & $16(34.0)$ & \\
\hline Mental health & & & & 0.0272 \\
\hline Poor & $6(4.0)$ & $3(3.0)$ & $3(6.1)$ & \\
\hline Fair & $15(10.0)$ & $9(8.9)$ & $6(12.2)$ & \\
\hline Good & 49 (32.7) & $27(26.7)$ & $22(44.9)$ & \\
\hline Very good & $50(33.3)$ & $36(35.6)$ & $14(28.6)$ & \\
\hline Excellent & $30(20.0)$ & $26(25.7)$ & $4(8.2)$ & \\
\hline Missing & 4 & 3 & 1 & \\
\hline $\begin{array}{l}\text { Mental health as } \\
\text { dichotomous }\end{array}$ & & & & 0.0045 \\
\hline Good or worse & $70(46.7)$ & $39(38.6)$ & $31(63.3)$ & \\
\hline $\begin{array}{l}\text { Very good or } \\
\text { better }\end{array}$ & $80(53.3)$ & $62(61.4)$ & I8 (36.7) & \\
\hline Missing & 4 & 3 & I & \\
\hline Overall health & & & & 0.4536 \\
\hline Poor & $15(10.0)$ & $10(9.9)$ & $5(10.2)$ & \\
\hline Fair & $35(23.3)$ & $19(18.8)$ & $16(32.7)$ & \\
\hline Good & $63(42.0)$ & $45(44.6)$ & $18(36.7)$ & \\
\hline Very good & $32(21.3)$ & $23(22.8)$ & $9(18.4)$ & \\
\hline Excellent & $5(3.3)$ & $4(4.0)$ & I (2.0) & \\
\hline Missing & 4 & 3 & 1 & \\
\hline Overall health as & & & & 0.3994 \\
\hline \multicolumn{5}{|l|}{ dichotomous } \\
\hline Good or worse & $113(75.3)$ & $74(73.3)$ & $39(79.6)$ & \\
\hline $\begin{array}{l}\text { Very good or } \\
\text { better }\end{array}$ & $37(24.7)$ & $27(26.7)$ & $10(20.4)$ & \\
\hline New medication & & & & 0.5162 \\
\hline No & $53(34.4)$ & 34 (32.7) & $19(38.0)$ & \\
\hline Yes & $101(65.6)$ & $70(67.3)$ & $31(62.0)$ & \\
\hline
\end{tabular}

Table I (Continued)

\begin{tabular}{|c|c|c|c|c|}
\hline & Overall & $\begin{array}{l}\text { Strongly } \\
\text { agree }\end{array}$ & $\begin{array}{l}\text { Not } \\
\text { strongly } \\
\text { agree }\end{array}$ & p-Value \\
\hline Nurse always & & & & $<0.0001$ \\
\hline \multicolumn{5}{|l|}{ communicated well } \\
\hline No & $39(25.3)$ & $16(15.4)$ & $23(46.0)$ & \\
\hline Yes & I I 5 (74.7) & $88(84.6)$ & $27(54.0)$ & \\
\hline Physician always & & & & 0.0002 \\
\hline \multicolumn{5}{|l|}{ communicated well } \\
\hline No & $29(18.8)$ & $\mathrm{II}(10.6)$ & $18(36.0)$ & \\
\hline Yes & $125(81.2)$ & $93(89.4)$ & $32(64.0)$ & \\
\hline
\end{tabular}

Note: Bold figures represent $p \leq 0.05$

Abbreviation: SD, standard deviation.

medications were prescribed to $65.6 \%$ of the patients during their hospital stay.

Significant relationships were observed between nurse communication and patient-reported understanding of medications at hospital discharge $(p<0.0001)$ and likewise with physician communication $(p=0.0002)$. There were no significant differences in patient-reported understanding of discharge medications between those prescribed new medications during the hospital stay and those who were not $(p=0.5162)$. Using logistic regression, we first examined relationships among explanatory variables of the patient reporting that "nurses always communicated well" and patients having had "new medications" prescribed during hospitalization, and the outcome of patients' strongly agreeing that they understood their "discharge medications." We ran a similar analysis for physician communication separately. Based on our hypothesis that new medication prescriptions would moderate perceptions of communication and understanding at discharge, we then included the interaction of new medication with each of the communication variables, but neither was statistically significant (nurse communication $p=0.8486$ and physician communicated $p=0.7983$ ).

Backward logistic regression was then conducted to examine these relationships after adjustment for other independent variables. The final regression model included the independent variables of the "nurse always communicates well," the physician always communicates well," "new medication during hospital stay," and the "indicator for very good or better mental health." The inclusion of interactions between the communication variables and new medication and between the communication variables and mental health was tested by a likelihood ratio test, which showed no evidence for better fit with the larger model, $X^{2}(4)=1.18$, $p=0.1191$. Regression coefficients are presented in Table 2 . The model correctly classified $72.6 \%$ of the cases with an effect size of 0.21 . Patients' perceptions of their discharge 
Table 2 Regression coefficients for model variables in classifying understanding of medications at hospital discharge

\begin{tabular}{|c|c|c|c|c|c|}
\hline Variable & $\begin{array}{l}\beta \text { (standard } \\
\text { error) }\end{array}$ & Wald $\chi^{2}$ & DF & p-Value & $\begin{array}{l}\text { Odds } \\
\text { ratio ( } 95 \% \\
\text { confidence } \\
\text { interval) }\end{array}$ \\
\hline Intercept & $-1.38(0.55)$ & 6.37 & 1 & 0.0116 & \\
\hline $\begin{array}{l}\text { Nurse always } \\
\text { communicates } \\
\text { well }\end{array}$ & $1.13(0.46)$ & 5.97 & I & 0.0145 & $\begin{array}{l}3.10 \\
(1.25,7.66)\end{array}$ \\
\hline $\begin{array}{l}\text { Physician always } \\
\text { communicates } \\
\text { well }\end{array}$ & $0.89(0.5 \mathrm{I})$ & 3.04 & I & 0.0813 & $\begin{array}{l}2.44 \\
(0.90,6.68)\end{array}$ \\
\hline $\begin{array}{l}\mathrm{New} \\
\text { medication }\end{array}$ & $0.34(0.40)$ & $0.7 \mathrm{I}$ & 1 & 0.4009 & $\begin{array}{l}1.40 \\
(0.64,3.08)\end{array}$ \\
\hline $\begin{array}{l}\text { Mental health: } \\
\text { very good or } \\
\text { better vs good } \\
\text { or worse }\end{array}$ & $0.77(0.39)$ & 3.99 & 1 & 0.0456 & $\begin{array}{l}2.17 \\
(1.02,4.64)\end{array}$ \\
\hline
\end{tabular}

medications were associated with reporting nurses "always" communicated (odds ratio [OR]: $3.10, p=0.015$ ) and very good or better mental health (OR: $2.1, p=0.046)$. Additionally, reporting physicians "always" communicated was associated with higher odds of understanding medications at hospital discharge, although this association was marginally nonsignificant (OR: 2.44, $p=0.081$ ).

\section{Discussion}

In this descriptive cross-sectional study, patients reported generally very strong agreement with understanding their medications at discharge, and these ratings were positively associated with both nurse communication and physician communication when tested in separate models. No association was found between whether or not patients had a new medication prescribed during their hospital stay and their understanding of their discharge medications.

We also found a positive, though weak, relationship between perceived mental and emotional health, and both perceptions of nurse communication and physician communication, but not understanding of discharge medications. Selfrated health status was associated with patient ratings of care, quality, and satisfaction, ${ }^{15-17}$ but Elliott et a ${ }^{18}$ suggested that these effects within individual hospitals are likely very small. These differences likely affect hospitals with a diverse population, which makes between-hospital comparison difficult. ${ }^{18} \mathrm{In}$ several studies, self-perceived health status was associated with patient ratings of health care satisfaction. In one study, actual admitting diagnoses were used to understand the association between health problems and perceptions of care. ${ }^{16}$ In another study, patients' perceptions of quality of care were significantly associated with satisfaction with care, but this finding was independent of health status. ${ }^{19}$ Manias et $\mathrm{al}^{20}$ found that patients may ask questions about medication changes, but deterioration in health status often affects engagement, which in turn determines the amount of information patients receive from health care providers. In our study, patients' perceived health status was generally reflective of a well population, which may also explain the positive perceptions of nurse communication and physician communication. Patients with psychosocial issues may not engage as often with health care providers.

The high ratings of understanding in this study indicate that patients believed they understood their medications at discharge. However, participants in this study were mostly older, and older patients are more likely to positively evaluate both communication and their understanding. ${ }^{21}$ Other studies have found that patients' perceptions of understanding their discharge instructions, including medications, do not indicate actual understanding in the older adult population. ${ }^{22,23}$ Ziaeian et $\mathrm{al}^{22}$ found that by interviewing patients aged 64 and over and asking them to name their medications, misunderstanding about medication changes, such as dose changes, new medications, and stopping medications, occurred as often as $88.7 \%$ of the time. Despite patients' perceptions of understanding each of their medications well, as observed in the present study, these perceptions may not accurately reflect patients' understanding.

\section{Limitations}

There are some limitations to the results presented in this study. This was a cross-sectional design, and therefore causality cannot be inferred from these data. Further, this is a small sample of data obtained from within one unique hospital; there would likely have been more variation across multiple hospitals. Goldstein et $\mathrm{a}^{24}$ reported that across multiple hospitals' HCAHPS score rankings, little variation existed in scores on both communications about new medications and discharge information scores - a consistent finding across patient subgroups. Although there were no differences between patient characteristics in those who were prescribed new medications and those who were not in our study, we had insufficient power to enter these variables into the model. New medication was not a statistically significant predictor of understanding of medications at hospital discharge, but this may be a result of the low statistical power (post hoc power $=13.4 \%$ ) in our study for an adjusted OR of 1.4 under the final presented in Table 2. Low power was also an issue for "physician always communicates well," but the corresponding effect was only marginally nonsignificant. These relationships, along with patient characteristics, 
need to be examined and confirmed in a larger study using multiple hospitals.

\section{Conclusion}

The results of this study emphasize that patients' perceptions of nurse communication are strongly associated with patients' self-reported understanding of discharge medication using HCAHPS data. Physician communication may also be associated with medication understanding, as our results were marginally nonsignificant. New medications prescribed during the hospital stay did not moderate patients' understanding of their medications at discharge, thus highlighting the significance of making sure patients understand all of their medications at discharge. These findings emphasize the overall need to provide clear communication throughout the hospital stay to build patients' understanding of their medications, while addressing psychosocial needs. While efforts to enhance patients' understanding of new medications during the hospital visit are important to help keep them informed, we did not find evidence to support the hypothesis that patients' understanding of the medications they need to take after hospital discharge are influenced by whether or not new medications were prescribed during the hospital stay. These findings can be used to inform development of nurse and physician communication training and interventions that facilitate communication and patient engagement in assisting patients to better understand their medications across the hospital stay. Because of the observed correlations among variables, focusing on one quality indicator, such as improving discharge medication understanding, can result in significant improvement in communication quality indicators. Training should include an emphasis on what health care providers say and how they present the information in a way that patients can understand and in a way that conveys respect and courtesy. Involving patients in the design of this training is one way to enhance patient-centeredness and align with patient needs. By using HCAHPS data, we were able to model these correlates of patients' understanding, which may be useful for designing health service interventions and monitoring outcomes. More effort to support patients' understanding of medications may be needed for patients who report poorer mental and emotional health. Interventions to promote patients' understanding of their medication should also consider addressing patient psychosocial needs and emotional well-being, while emphasizing clearly and understanding health care provider communication about medications across the hospital stay.
Further, we suggest that findings such as these should be discussed with patient advisory boards in planning effective quality improvement efforts.

\section{Acknowledgments}

The authors would like to thank Dr Phyllis Dexter for her feedback, language, and formatting edits of this manuscript. This study was supported by the Center for Enhancing Quality of Life and Chronic Illness at Indiana University School of Nursing at Indianapolis. The opinions, results, and conclusions reported in this paper are those of the authors and are independent from the funding and data sources.

\section{Disclosure}

The authors report no conflicts of interest in this work.

\section{References}

1. Armor BL, Wight AJ, Carter SM. Evaluation of adverse drug events and medication discrepancies in transitions of care between hospital discharge and primary care follow-up. J Pharm Pract. 2016;29(2):132-137.

2. U.S. Department of Health and Human Services. Medication Error Reports. Washington, DC; 2016. Available from: http://www.fda. gov/Drugs/DrugSafety/MedicationErrors/ucm080629.htm. Accessed November 10, 2016.

3. Harris CM, Sridharan A, Landis R, Howell E, Wright S. What happens to the medication regimens of older adults during and after an acute hospitalization? J Patient Saf. 2013;9(3):150-153.

4. Shiu JR, Fradette M, Padwal RS, et al. Medication discrepancies associated with a medication reconciliation program and clinical outcomes after hospital discharge. Pharmacotherapy. 2016;36(4):415-421.

5. Boulding W, Glickman SW, Manary MP, Schulman KA, Staelin R. Relationship between patient satisfaction with inpatient care and hospital readmission within 30 days. Am J Manag Care. 2011;17(1):41-48.

6. Bartlett Ellis RJ, Bakoyannis G, Haase JE, Boyer K, Carpenter JS. Patient perceptions of provider and hospital factors associated with new medication communication. West J Nurs Res. 2016;38(9):1139-1154.

7. Batbaatar E, Dorjdagva J, Luvsannyam A, Savino MM, Amenta P. Determinants of patient satisfaction: a systematic review. Perspect Public Health. 2016:1757913916634136.

8. HCAHPS. HCAHPS Fact Sheet, 2009. Available from: http://www. hcahpsonline.org/files/HCAHPS $\% 20$ Fact $\% 20$ Sheet, $\% 20$ revised $1, \% 20$ 3-31-09.pdf. Accessed April 19, 2016.

9. Giordano LA, Elliott MN, Goldstein E, Lehrman WG, Spencer PA. Development, implementation, and public reporting of the HCAHPS survey. Med Care Res Rev. 2010;67(1):27-37.

10. Centers for Medicare \& Medicaid Services. HCAHPS Survey. Baltimore, MD: Centers for Medicare \& Medicaid Services; 2014.

11. Centers for Medicare \& Medicaid Services. HCAHPS Quality Assurance Guidelines V10.0. Baltimore, MD; 2015; Available from: http://www. hcahpsonline.org/Files/QAG_V10_0_2015.pdf. Accessed August 18, 2015.

12. Press Ganey. Frequently Asked Questions About HCAHPS. 2015; Available from: http://www.pressganey.com/researchResources/governmentInitiatives/HCAHPS/faqs.aspx - q11. Accessed August 18, 2015.

13. Henson RK. Understanding internal consistency reliability estimates: a conceptual primer on coefficient alpha. Meas Eval Couns Develop. 2001;34(3):177.

14. Peterson RA. A meta-analysis of Cronbach's coefficient alpha. $J$ Cons Res. 1994:381-391. 
15. Elliott MN, Zaslavsky AM, Goldstein E, et al. Effects of survey mode, patient mix, and nonresponse on CAHPS ${ }^{\circledR}$ hospital survey scores. Health Serv Res. 2009;44(2 Pt 1):501-518.

16. Hargraves JL, Wilson IB, Zaslavsky A, et al. Adjusting for patient characteristics when analyzing reports from patients about hospital care. Med Care. 2001;39(6):635-641.

17. Rahmqvist M, Bara AC. Patient characteristics and quality dimensions related to patient satisfaction. Int J Qual Health Care. 2010:22(2): 86-92.

18. Elliott MN, Lehrman WG, Goldstein E, Hambarsoomian K, Beckett MK, Giordano LA. Do hospitals rank differently on HCAHPS for different patient subgroups? Med Care Res Rev. 2010;67(1):56-73.

19. Zapka JG, Palmer RH, Hargraves JL, Nerenz D, Frazier HS, Warner CK. Relationships of patient satisfaction with experience of system performance and health status. J Ambul Care Manage. 1995;18(1): 73-83.
20. Manias E, Rixon S, Williams A, Liew D, Braaf S. Barriers and enablers affecting patient engagement in managing medications within specialty hospital settings. Health Expect. 2015;18(6):2787-2798.

21. DeVoe JE, Wallace LS, Fryer Jr GE. Measuring patients, Äô perceptions of communication with healthcare providers: do differences in demographic and socioeconomic characteristics matter? Health Expect. 2009;12(1):70-80.

22. Ziaeian B, Araujo KL, Van Ness PH, Horwitz LI. Medication reconciliation accuracy and patient understanding of intended medication changes on hospital discharge. J Gen Intern Med. 2012;27(11):1513-1520.

23. Horwitz LI, Moriarty JP, Chen C, et al. Quality of discharge practices and patient understanding at an academic medical center. JAMA Intern Med. 2013;173(18):1715-1722.

24. Goldstein E, Elliott MN, Lehrman WG, Hambarsoomian K, Giordano LA. Racial/ethnic differences in patients' perceptions of inpatient care using the HCAHPS survey. Med Care Res Review. 2010;67(1):74-92.
Nursing: Research and Reviews

\section{Publish your work in this journal}

Nursing: Research and Reviews is an international, peer-reviewed, open access journal publishing original research, reports, reviews and commentaries on all aspects of nursing and patient care. These include patient education and counseling, ethics, management and organizationa issues, diagnostics and prescribing, health outcomes, economics and

\section{Dovepress}

resource management, improving patient safety in all settings. The manuscript management system is completely online and includes a very quick and fair peer-review system. Visit http://www.dovepress. $\mathrm{com} /$ testimonials.php to read real quotes from published authors. 